\title{
ARTICLE \\ A Risk Characterization of Regulatory Arbitrage in Financial Markets
}

\section{Andrea Minto ${ }^{1,2,3} \cdot$ Stephanie Prinz ${ }^{4} \cdot$ Melanie Wulff ${ }^{4}$}

Accepted: 22 June 2021 / Published online: 2 August 2021

(c) The Author(s) 2021

\begin{abstract}
This article analyses regulatory arbitrage in financial markets from a risk-based perspective. It assesses regulatory arbitrage in terms of the risk it may pose to the attainment of a regulatory objective, in this case financial stability. Its most distinct contribution to the literature is the application of the NOAEL approach-thus far mainly used in public health literature and regulatory toxicology - to the legal analysis and management of arbitrage risks. We propose several qualitative parameters relating to the likelihood of regulatory arbitrage and the negative impact if such arbitrage should occur. The article ultimately aims to help frame the ongoing debate about policy-making and the use of risk assessment methodologies to cope with regulatory arbitrage in financial markets.
\end{abstract}

Keywords Regulatory arbitrage $\cdot$ Risk characterization $\cdot$ Regulatory toxicology NOAEL · Financial stability

\section{Introduction}

Scholars usually characterize regulatory arbitrage as the exploitation of discrepancies between the economic substance and the legal treatment of transactions, products and services. Partnoy, for instance, describes regulatory arbitrage as the choice between different business strategies that account for an economically equivalent position. Specifically, he explains how regulatees restructure non-derivative

\footnotetext{
The views expressed in this article represent the authors' personal opinions and do not necessarily reflect the views of the Deutsche Bundesbank or its staff. The European Commission's support for the production of this publication does not constitute an endorsement of the contents, which only reflect the views of the authors, and the Commission cannot be held responsible for any use which may be made of the information contained therein. Although this article is the result of a joint reflection, Sects. 1, 2, 3, 5 and 8 can be primarily attributed to Andrea Minto, with the remaining sections primarily attributable to Stephanie Prinz and Melanie Wulff.
}

Andrea Minto

andrea.minto@unive.it

Extended author information available on the last page of the article 
transactions in order to form equivalent derivative transactions and thus avoid costly regulation. ${ }^{1}$ Along the same lines, Turk highlights how an activity can be repackaged to fit under a lax regulatory regime, while maintaining the economic substance of the deal. He explains that the way to attain this lenient treatment is to re-characterize an activity so that it crosses either the boundary line of a definition or a jurisdiction, and moves to a less regulated side. ${ }^{2}$ Beyond inconsistencies between regulatory regimes, the literature attributes substantial significance to the structure of a transaction due to the gaps between business practice and its regulatory treatment. In other words, regulatory arbitrage amounts to the manipulation of the form of the transaction in order to exploit the loopholes created by the discrepancy between the economic substance and the legal framework that strives to capture it. ${ }^{3}$ If 'arbitrage is an "art of association" of two things - a similarity and a difference', as elegantly put by Riles, then performing this 'art' is made easier if:

(i) financial markets are interconnected, which leads to a functional similarity between financial transactions, products and services;

(ii) there is a fundamental difference between the laws governing these transactions, products and services, ${ }^{4}$ and

(iii) there is a polycentric regulatory system in which most areas are regulated and supervised by multiple regulators and agencies with overlapping responsibilities. $^{5}$

Regulatory arbitrage has been thoroughly studied from the perspective of arbitrageurs. The key components of such studies include the behaviour, attitude and culture of the firm or individual (i.e. rent-seeking behaviour) attempting to exploit legal

\footnotetext{
1 Partnoy (1997), p 227.

2 Turk (2015), p 967. See also Fleischer (2010), p 227: Legal, ethical, professional, political constraints and transaction costs are to be seen as constraints that tend to diminish the effects of regulatory arbitrage. By using examples from the US jurisdictional system, he points out the importance, albeit imperfectness, of anti-abuse rules as legal impediments that can prevent regulatory arbitrage. He concedes that they aim at addressing future regulatory arbitrage opportunities that the legislator cannot foresee beforehand. When a legal provision seems to be weak and easily manipulated, these anti-abuse rules can make a difference.

3 Barry (2011), p 73.

4 Riles (2014), p 63. Regulatory arbitrage does not demand two identical economic transactions. Two close economic substitutes should suffice. In addition, sometimes arbitrageurs pursue strategic substitutes, with an eye to obtaining supplementary benefits.

5 On the other hand, classic public choice scepticism about the regulatory state, based on theories of rent-seeking, rent extraction and regulatory capture, is based on the unrealistic, and usually unstated, assumption of a monopolist regulator. See Tarko and Farrant (2019).
} 
loopholes and inconsistencies within, and between, jurisdictions. ${ }^{6}$ Albeit essential, this approach remains a partial one, and hence does not fully capture the topic.

We intend to contribute to the debate by characterizing regulatory arbitrage by the risk it poses - if it occurs - to the attainment of a regulatory objective. For the purpose of this analysis, the regulatory objective we are concerned with is the stability of the financial system.

The novelty of this study lies in the application of the 'NOAEL/safety factor approach'-thus far chiefly examined in public health scholarship and regulatory toxicology - to the legal analysis and management of risks resulting from arbitrage. Such an approach allows for the introduction of the idea of the 'acceptability' of a certain level of risk in situations of cause-effect uncertainty that policy makers may be facing. Toxicological approaches to risk assessment expose and characterize causal relations between risks and consequences. They serve as evaluative aids for the design of policy and regulation by way of setting thresholds of acceptable risks. Thus, regulatory toxicology strives to set acceptability thresholds that-with the incorporation of uncertainty factors-define doses that are extremely unlikely to have negative effects on human health. These thresholds aim to formalize a system of qualitative values below which a very low probability of an appreciable risk to human health (or the ecosystem) exists. The 'no observed adverse effects level' (NOAEL) method does not eliminate the possibility of harm stemming from a regulatory policy, but it does provide a reasonable degree of assurance-a 'reasonable certainty' - that there will be no or very little harm. This approach has hence been adapted for the identification of indices for the probability and the impact of regulatory arbitrage in financial markets. As a result, we have developed a 'traffic light' system which aims at drawing a line between what can be expected to be harmful for financial stability (red light), and what can be considered to have an insignificant impact or no impact at all (green light). From this perspective, the fundamental objective is to determine a safe level of exposure to risks from regulatory arbitrage present in the 'regulatory environment' of financial markets, similar to the fundamental problem of toxicology of determining safe levels of exposure to toxicants present in the environment.

The remainder of this article is structured as follows: Section 2 provides an overview of the features of regulatory toxicology approaches, with a special focus on the NOAEL methodology. Section 3 puts forward a risk-based framework for assessing regulatory arbitrage in financial markets by defining its three components: 'probability', 'impact', and 'regulatory objective'. Section 4 maps out the conditions for, and the causes of, regulatory arbitrage. Sections 5 and 6 elaborate on 'probability' and 'impact', respectively. Section 7 incorporates the NOAEL approach in order to

\footnotetext{
6 The rent-seeking behaviour of arbitrageurs has been considered as an indispensable element for regulatory arbitrage to occur, Posner and Weyl (2012). Arbitrageurs aim at gaining profit even if it entails restructuring costs; see i.e. Dobris (2004), p 439. From this vantage point, regulatory arbitrage seems to provide a cost-efficient alternative to burdensome regulation. It can be regarded as a profit-driven activity by any actor capable of engaging therein who aims at exploiting gaps in legislation that fail to capture the business reality, or gaps that stem from inconsistencies identified due to different regulatory treatment. This delineation has gone some way towards creating an all-inclusive definition, with all the limitations of 'one size fits all' approaches.
} 
set acceptability thresholds and Section 8 explains the policy implications. Section 9 applies the risk-based framework to examine potential financial stability risks originating from regulatory arbitrage in the Libra network. Section 10 concludes.

\section{A Risk Characterization of Regulatory Arbitrage: Importing the NOAEL Approach}

The basic idea of managing risk resulting from arbitrage can be simple: an arbitrage opportunity is worth policy consideration when it is capable of causing financial stability concerns. In practice, however, measuring-let alone quantifying - the likelihood of such a risk occurring and the actual implications it may have can be a complex task. This is due to a host of political, economic and regulatory factors that play a role in creating an arbitrage opportunity. ${ }^{7}$

Other policy areas that also face high uncertainty can provide inspiration, for instance environmental law, food safety law, and health and safety regulation. Characterizing the right hazards, their probability of materializing, and the respective costs they may impose on health and/or the environment is a task plagued by uncertainty, which is shorthand for a whole array of methodological, informational, epistemological and even ontological problems in determining the level of risk. ${ }^{8}$ Experimental and sampling uncertainties in the collection of data affect the ecological and health context, since risk characterizations are typically influenced by variability in the exposures and dose-response assessments. ${ }^{9}$

In such an environment of uncertainty, policy makers opt for risk policies that appear 'to be the best choice in the absence of data to the contrary'. ${ }^{10}$ This has been the case, for instance, in health risk valuations where policy makers have turned to the use of uncertainty factors in estimating carcinogenic risk. ${ }^{11}$ Assumptions can often exert significant influence on risk characterization, playing a critical role in helping to 'move along' the process of risk assessment when data is lacking. ${ }^{12}$

Despite this uncertainty, regulators developed methods that are suitable for the underlying variability in the data which aim to ensure that the public and the environment are not exposed to unacceptable risks. ${ }^{13}$ Of course, this requires a judgment as to what level of risk for a certain hazard is deemed acceptable. ${ }^{14,15}$ When drawing the line of acceptability, the legal and administrative framework for standard setting

\footnotetext{
7 Partnoy (2019).

8 Wynne (1992); Smithson (1993).

9 Carpenter (1995).

10 National Research Council (NRC) (1983), p 63.

11 National Research Council (NRC) (2009), especially chapter 6, pp 188-212, for the selection and use of various default options in risk assessment.

12 Hodgson (2015).

13 Recently, EFSA (2017).

14 The UK Health and Safety Executive, in its description of HSE's decision-making process, qualifies standards as 'generic control measures that must be applied to eliminate or reduce the risks for a particular hazard'.

15 On the concept of acceptability, see also Timur and Sunstein (1999).
} 
has to consider a number of different factors, ranging from public perception, statistical data, new information concerning new risks, the political setting, and ethical considerations. ${ }^{16}$

Toxicologists, for instance, start from two assumptions. First, the level of risk depends on the level of exposure. Second, overexposure to almost any substance can pose serious health risks. 'The fundamental problem of toxicology is thus to determine safe levels of exposure to toxicants present in the environment. ${ }^{17}$ Although conceptually straightforward, the safety evaluation process is fraught with uncertainty. Indeed, regulatory uncertainties hinge upon the notion of safety itself: is absolute safety an achievable goal or are small risks coupled with offsetting benefits acceptable? The legal uncertainties inherent in the statutes under which safety evaluation is mandated can therefore be rephrased in the very concept of 'acceptability', which can be substantiated thanks to qualitative parameters by applying a suitable 'safety' or 'uncertainty factor' to that dose level at which no adverse effects were observed in toxicological studies. ${ }^{18}$

In this vein, public health scholars and regulatory agencies have developed what is known as a 'safety factor approach'. ${ }^{19}$ Put simply, it means that a threshold is computed based on available evidence and then divided by a safety factor in order to account for individual differences in the threshold. One common variant of this approach is NOAEL, which some health and safety regulatory agencies have employed to regulate non-carcinogens. ${ }^{20}$ For example, the US Food and Drug Administration (FDA) licenses non-carcinogenic food additives so that the 90th percentile exposure is no greater than the NOAEL observed in animal tests, divided by a safety factor. $^{21}$

The NOAEL for non-carcinogens has been developed based on data from computational studies, but most importantly by drawing on published studies and unpublished technical reports produced by both government and industry. ${ }^{22}$ It has led toxicologists to ascertain that each individual has a physiological threshold below which exposure will determinately not cause any harm. However, because the regulator is not omniscient, it cannot be absolutely certain that a given (non-zero) exposure of some individual to a non-carcinogen is below that individual's threshold. ${ }^{23}$ 'The technique of dividing the NOAEL by a safety factor [in order to account for the

\footnotetext{
16 Fisher (2000); see e.g. Krimsky and Golding (1992); Douglas and Wildavsky (1982).

17 Krewski et al. (1984).

18 Dourson and Stara (1983); Miller et al. (1983).

19 Recently, there has been an intense discussion on the implementation and integration of new testing systems and approach methods into a regulatory framework for regulatory toxicology. Arnot et al. (2012); Kavlock et al. (2012); Lilienblum et al. (2008).

${ }^{20}$ Rodricks et al. (1991); Brock et al. (2003).

21 Adler $(2005,2006)$.

22 Kalberlah and Schneider (1998); World Health Organization (WHO) (1994, 1999, 2009); Hodgson (2015), p 205.

23 Adler (2007).
} 
heterogeneity in thresholds among humans] is a way to arrive at an exposure level that the regulator is reasonably certain will not cause harm. ${ }^{24}$

Of course, the NOAEL/safety factor method does not eliminate the possibility of harm stemming from exposure to a substance, and over time the toxicology literature has pointed out some limitations of this approach. ${ }^{25}$ Nonetheless, the NOAEL does provide a reasonable degree of assurance - a 'reasonable certainty' - that there will be no harm. Such methodology tends to achieve an 'objective and balanced' risk characterization. ${ }^{26}$

Applying this approach to the assessment of regulatory arbitrage seems promising. The NOAEL method is generally considered prudent and protective whilst not drawing a sharp line between absolute safety and hazard. ${ }^{27}$ Despite the asserted 'reasonable certainty' that there will be no harm, scientists also recognize that there remains some residual risk. However, the approach enables a legal and factual interpretation of acceptable risk vis-à-vis the regulatory objective pursued.

In order to operationalize the NOAEL approach in the financial stability context, we are developing a theoretical framework in three steps. First, we have to define risk that may result from regulatory arbitrage by decomposing it into two parts: probability and impact. We then develop a number of indicators for both probability and impact. Finally, we consider how we can use the indicators to help us approximate a NOAEL threshold.

Such a risk assessment methodology can contribute to developing a theory as a guide to understanding key risk-specific issues. In other words, a risk characterization of regulatory arbitrage aims at forcing policy makers and regulatory agencies to put into context the risks they regulate.

\section{A Risk-Based Framework for Assessing Regulatory Arbitrage in Financial Markets}

We propose a framework that assesses the risks that firms' engagement in regulatory arbitrage may pose to financial stability. In practice, it draws upon standard risk management systems: probability that an arbitrage opportunity is exploited and the

\footnotetext{
24 Adler (2005), p 1156; see also, e.g., Cross et al. (1991).

25 See, e.g., Esdaile (1995); EFSA (2017); Rezvanfar (2014), who specify that 'using the NOAEL approach to estimate acceptable human exposure values such as RfDs and RfCs has several limitations: (1) it must be one of the tested experimental doses, so it depends on the study design and once this dose is identified, the rest of the dose-response curve is ignored; (2) it does not account for variability in the estimate of the dose-response. In essence, the NOAEL is very sensitive to sample size and there can also be high variability among experiments; (3) it does not account for the slope of the dose-response curve; and (4) it cannot be applied when there is no NOAEL, except through the application of an uncertainty factor when an LOAEL is used.'

26 See United States Environmental Protection Agency (2000).

27 The use of safety factors is based on the observation that toxic substances usually have thresholds below which toxic effects cannot be detected. The safety factor attempts to account for differences between animals and humans and differences in sensitivity among humans. The use of the safety factor is intended to provide an adequate margin of safety for consumers.
} 
potential significance (or magnitude) of the impact if an associated risk materializes. By analyzing the two elements, one can assess the necessity of placing the issue on the policy agenda: it may suffice if just one of these elements reaches concerning levels.

Similar to toxicologists, we strive to operationalize parameters to set a threshold for the acceptability of the risk of regulatory arbitrage. In this way, we can acknowledge and accommodate uncertainties relating to the likelihood of arbitrage occurring and the impact it could have if associated risks materialize (corresponding to inter-individual differences in susceptibility and exposure in health and regulatory toxicology). ${ }^{28}$ This means that due to large gaps in the available data-similar to health and environmental studies-we propose using qualitative parameters from various government and industry sources, be they scientific or anecdotal evidence.

By providing a structured approach, our framework can improve risk management with regard to regulatory arbitrage. Impact and probability scores are combined into a rating system (e.g. a 'traffic light' system) that is meant to frame the regulatory stance, i.e. the actions the regulator should consider taking with respect to a specific risk, and how 'strict' or 'lenient' they should be in their attitudes towards it.

This characterization of regulatory arbitrage hence puts emphasis on the following elements:

(i) probability

(ii) impact

(iii) regulatory objective (in this case, financial stability)

(i) Probability refers to the odds of an arbitrage opportunity being exploited. The arbitrage opportunity is a regulatory situation that opens up the possibility for entities to take advantage of differences in the regulatory treatment of transactions, products or services, i.e. to engage in arbitrage behaviour. Such a regulatory situation requires that two enabling elements co-exist: a) a functional (or economic) similarity among transactions, products or services so that one can be substituted for another; and (b) a (relatively) stable formal difference of some kind. ${ }^{29}$

(ii) Impact describes the possible consequences if the arbitrage opportunity is exploited and some associated risk materializes.

(iii) Finally, the risk has to be considered in relation to the regulatory objective. For the purpose of this paper, the regulatory objective is financial stability, which we

\footnotetext{
${ }^{28}$ FDA (2007). For non-cancer endpoints, the no-observed-effect level (NOEL) is divided by a safety factor to obtain an estimate of the maximum acceptable daily intake (ADI) of the additive for humans. The selection of a safety factor is based on the biological significance of the endpoint, uncertainties inherent in extrapolating information about adverse effects from toxicity studies in animals to human populations, and other judgmental factors. The food additive procedural regulations (21 CFR 170.22) state that a safety factor of 100 will be used as a general rule in applying animal test data to man. However, exceptions to a safety factor of 100 are permitted in accordance with the nature and extent of available data and the circumstances concerning the use of the food additive. For example, safety factors may be modified because of potentially sensitive sub-populations such as children, geriatrics, individuals with deficiency states, and a lack of developed enzyme metabolic systems.

29 We elaborate upon the definition by Riles (2014).
} 
define as 'a state in which the financial system can perform its key economic functions smoothly at all times, particularly in times of stress and structural upheaval'. ${ }^{30}$ It becomes the yardstick for examining the consequences of regulatory arbitrage practices.

Viewed through this prism, arbitrage becomes a nuanced concept. It moves from the paradigm that market participants are busy devising new ways of circumventing the law to a critical assessment aimed at identifying those cases that could pose a concrete threat, a material risk to a regulatory objective, i.e. to financial stability.

This approach sheds light on the magnitude of risks that arbitrage opportunities may entail. It shifts the debate by raising a crucial yet largely neglected question: how do we draw a line between 'good'-or 'neutral' - and 'bad' regulatory arbitrage, and when should the regulators care and try to limit or eliminate it? ${ }^{31}$

The next sections of the paper will discuss the conditions for and the causes of regulatory arbitrage. This is necessary in order to identify the qualitative and descriptive parameters.

\section{Conditions for, and Causes of, Regulatory Arbitrage}

We identify five conditions that could give rise to regulatory arbitrage opportunities: (i) regulatory regime inconsistency; (ii) time inconsistency; (iii) economic substance inconsistency; (iv) interpretative inconsistency; and (v) information asymmetry (Table 1). These conditions are not cumulative, since only one of them has to be satisfied for an arbitrage opportunity to arise.

(i) Regulatory regime inconsistency refers to situations where the same transaction is treated differently in two regulatory regimes, whether these regimes belong to the same jurisdiction or to different ones. Within the same jurisdiction, an inconsistency can occur when two different fields of law regulate an activity or a product. The actors may then be able to choose the most appropriate (or convenient, or beneficial) regime. Fleischer calls this situation 'doctrinal' inconsistency. For instance, a financial instrument may be designed in such a way that it is treated as a debt for tax purposes, but as equity for purposes of capital requirements instituted by financial regulators. ${ }^{32}$ Regulatory inconsistency among different countries can also result in the relocation of businesses or activities, with the choice of jurisdiction being based on such legal inconsistency. ${ }^{33}$ An example is a transaction that may be prohibited or strictly regulated in one country, but may be lightly regulated in another; thus firms

\footnotetext{
30 See the Deutsche Bundesbank policy in this respect: https://www.bundesbank.de/en/tasks/financialand-monetary-system/financial-and-monetary-stability. The topic of financial stability has been extensively studied by the literature, in particular in relation to systemic risk. See e.g. Oosterloo and de Haan (2003); Weiß et al. (2014); Amorello (2018); Benoit et al. (2017); Smaga (2014); Butzbach (2016); Freixas et al. (2015); FSB, IMF, BIS (2011); International Monetary Fund (2013).

31 As Riles puts it, 'A more appropriate understanding of arbitrage therefore would begin with the proposition that some forms of legal pluralism are very much worth defending, but others are not, and hence that some forms of arbitrage are very much worth opposing, but others are not': Riles (2014), p 74.

32 Cauble (2017).

33 Miyazaki (2013), p 36.
} 
Table 1 Conditions for regulatory arbitrage
Conditions for regulatory arbitrage

(i) Regulatory regime inconsistency

(ii) Time inconsistency

(iii) Economic substance inconsistency

(iv) Interpretative inconsistency

(v) Information asymmetry

will aim for the more lightly or unregulated jurisdiction. Essentially, this activity constitutes forum shopping.

(ii) Time inconsistency refers to a difference in the regulatory treatment of a transaction across time. Due to legislative changes over time and transitional periods, actors might have the opportunity to decide which law, old or new, will apply to them. However, Barry ${ }^{34}$ points out that time inconsistency can be a subset of regulatory regime inconsistency. He provides the example of a discrepancy between the Internal Revenue Code of 1954 and that of 1986. These could either be considered the same regulatory regime (i.e. tax law) at different times, or separate regulatory regimes, in which case they would constitute regulatory regime inconsistency.

(iii) Economic substance inconsistency occurs, for instance, when 'two transactions with identical cash flows receive different regulatory treatment under the same regulatory regime'. This means that the law does not take the economic substance of the transactions into account. ${ }^{35}$ To illustrate this type of inconsistency, Fleischer uses the example of a party interested in the economic cash flow associated with an asset: '[T] hat party may be more or less indifferent between owning the asset outright, leasing the asset for a long period of time, entering into a forward contract to buy the asset, or buying a call option and writing a put option on the asset'.

(iv) Interpretative inconsistency refers to the frequent disconnection between the letter and the spirit of the law. The letter of the law concerns its literal meaning, while the spirit of the law refers to its intention. ${ }^{36}$ The letter of the law does not always clearly reflect its spirit and thus allows for what McBarnet and Whelan call "creative compliance- using the law to escape legal control without actually violating the rules' ${ }^{37}$ Consequently, arbitrageurs manage to comply formally with the regulation without reaching its desired outcome. ${ }^{38}$ As opposed to economic substance inconsistency, the discrepancy here arises from legal formalism, ${ }^{39}$ the indeterminacy of language, ${ }^{40}$ necessary

\footnotetext{
34 Barry (2011).

35 Fleischer (2010).

36 Garcia et al. (2014), pp 479-480.

37 McBarnet and Whelan (1991), p 848.

38 Burk (2016).

39 Nabilou and Pacces (2015). Legal formalism is explained by the authors as 'the letter of a rule, even if this fails to serve its purpose' (p. 196).

${ }^{40}$ Hart (1961).
} 
generalizations ${ }^{41}$ and the fact that 'even the least vague terms may become vague upon their application to a particular situation that was not predictable when the rule was made'. ${ }^{42}$

In a similar vein, the existence of discrepancies between its letter and its spirit often renders law incomplete. Problems due to legal incompleteness are ubiquitous. ${ }^{43}$ Incompleteness appears in different dimensions and any kind thereof can give rise to regulatory arbitrage. ${ }^{44}$ A law can be incomplete if it fails to encompass all the activities that lead to the same damaging consequences. Therefore, even when the outcomes that shall be prevented are specified, law is still incomplete if it cannot capture all the actions that lead to those outcomes. ${ }^{45}$ Moreover, the wording of the law plays a crucial role. Incompleteness of the law can be ascribed to its vagueness, which can cloud its boundaries. Conversely, completeness is satisfied if a law enacted today unambiguously stipulates for all future contingencies' ${ }^{46}$ Nonetheless, it is impossible to foresee all future contingencies. This holds especially true in the financial sector, where the pace of innovation makes it particularly hard for the legislator to design laws.

Finally, drafters of rules are afflicted by cognitive and temporal constraints (i.e. bounded rationality) which undermine their ability both to draft rules that encompass all future contingencies and to foresee the unintended consequences of their drafting choices. In fact, legislators do not have much information about the future state of markets and society, ${ }^{47}$ and especially about the inventive forces that will try to bend the law. As Dan Awrey points out,

rules are by their very nature either over-inclusive (capturing behaviors which should be excluded) or under-inclusive (failing to capture behaviors which should be included). To the extent of this over- and/or under-inclusiveness, rules generate incentives that are incongruent with their purposes. More specifically, this emphasis of form over substance incentivizes those subject to rules to engage in (1) activities up to the boundary of permissible conduct, and

(2) welfare reducing creative compliance and regulatory arbitrage. ${ }^{48}$

Unintended consequences and novelties in the legal system are ubiquitous. ${ }^{49}$ Economic conditions can change in unexpected ways. There are many imponderables that law cannot capture in advance. Trying to anticipate all the creative ways in which the arbitrageurs will seek to undermine it is a futile endeavour.

\footnotetext{
41 See Raz (1979), pp 214-218. In an attempt to include every situation, laws tend to be general. Generality, however, comes at a price: when the law is broad, it is highly probable that it will be misinterpreted.

42 Black (1997), pp 12-13.

43 Bowers (2002); Pistor and Xu (2003).

44 Goyal (2017), p 344.

45 Pistor and Xu (2003), p 941.

46 Ibid.

47 Adler (2005), p 1250.

48 Awrey (2011).

49 Devins et al. (2015), pp 609, 613 and 661.
} 
(v) Information asymmetry is another important factor that can facilitate regulatory arbitrage. Lawmakers and regulators often lack crucial information. In the words of Julia Black, 'government cannot know as much about industry as industry does about itself' ${ }^{50}$ Industries gather expertise and technical knowledge through their day-to-day business, while regulators usually lag behind because they often lack this high level of expertise. As a result, they fail to observe and predict how legislation can be circumvented innovatively. Fleischer also captures this notion when he notes that 'regulatory arbitrage techniques are often unknown to policy makers and the public'. ${ }^{51}$ Hence, it can be argued that information asymmetry can perpetuate regulatory arbitrage.

The conditions discussed can manifest themselves in three types or categories of regulatory arbitrage: (i) cross-sectoral arbitrage; (ii) intra-sectoral arbitrage; and (iii) cross-jurisdictional arbitrage (Table 2).

Cross-sectoral arbitrage, also referred to as cross-framework arbitrage, describes what Nouy calls 'jumping sectoral fences'. ${ }^{52}$ It emerges when parts of the financial system, such as the banking sector, are heavily regulated, while other parts, such as the so-called shadow-banking sector, are less regulated or even unregulated. An example is banks that shift exposures to entities that are not consolidated for prudential purposes. In this context, Charles Goodhart notes that if regulation were effective, it would constrain the regulated entities from achieving their preferred, unrestricted position, often by lowering their profitability and their return on capital. This prompts regulated entities to open up connected operations in the non-regulated (or less regulated) sector to enable them to take advantage of better opportunities there (the cherry-picking phenomenon). ${ }^{53}$

However, it is not always necessary for entities to jump sectoral fences. Sometimes it is possible to exploit differences within a single set of rules. This phenomenon is commonly referred to as intra-sectoral arbitrage or inter-framework arbitrage. ${ }^{54}$ An example is banks that have a higher cost of equity trying to use internal models in order to decrease their risk-weighted assets that have to be financed by equity. $^{55}$

Cross-jurisdictional arbitrage comes about when rules in one country are less strict than in another. Goodhart argues that 'any constraint, or tax, that is imposed on a financial transaction in a country can often be (easily) avoided by arranging for that same transaction to take place under the legal, tax and accounting jurisdiction of another country, sometimes, indeed often, under the aegis of a subsidiary, or branch, of exactly the same bank or intermediary as was involved in the initial country, ${ }^{56}$ It is often argued that this may give rise to a regulatory race to the bottom between

\footnotetext{
50 Black (2001), p 107.

51 Fleischer (2010), p 282.

52 Nouy (2017).

53 Goodhart and Lastra (2010), p 706.

54 Jokivuolle (2018).

55 Beltratti and Paladino (2016).

56 Goodhart and Lastra (2010), p 715.
} 
Table 2 Types of regulatory arbitrage

Conditions for regulatory arbitrage
i. Regulatory regime inconsistency
ii. Time inconsistency
iii. Economic substance inconsistency
iv. Interpretative inconsistency
v. Information asymmetry

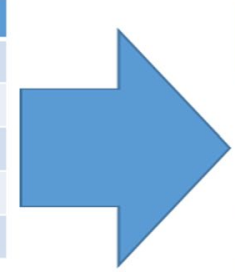

Types or categories of regulatory arbitrage

a. cross-sectoral arbitrage

b. intra-sectoral arbitrage

c. cross-jurisdictional arbitrage

jurisdictions. However, Carruthers and Lamoreaux survey the literature and find that true regulatory competition-when firms migrate in response to geographic differences in the costs and benefits of regulation, and governments shape their regulatory policies with the aim of affecting those migration flows-is rare. ${ }^{57}$

\section{Probability Parameters}

Given that a fundamental condition for regulatory arbitrage exists, the probability of this opportunity being exploited depends on several factors: the degree of centralization in law making, the degree of flexibility in the regulatory system, the degree of substitutability between transactions, products and services, and whether compliance costs or restructuring costs are higher (see Table 3 below).

\subsection{Degree of Centralization in Law Making}

The level of governance-centralized versus decentralized-can discourage or encourage regulatory competition. ${ }^{58}$ Decentralization alleviates information asymmetries, reduces the likelihood of regulatory capture, and induces more innovation and differentiated and customized services adapted to local circumstances and the needs of the constituency. ${ }^{59}$ It also opens up opportunities for regulatory arbitrage because it provides regulatory substitutes for regulated firms ${ }^{60}$ Ceteris paribus, in a more centralized system, the likelihood of regulatory arbitrage occurring should be lower than in decentralized systems.

\subsection{Degree of Flexibility in the Regulatory System}

Frantz and Instefjord analyze the relative strengths and weaknesses of principlesbased regulation vs. rules-based regulation, and how regulators in both cases

\footnotetext{
57 Carruthers and Lamoreaux (2016).

58 Arcuri and Dari-Mattiacci (2010).

59 Geradin and McCahery (2005).

60 Thiemann and Tröger (2020).
} 


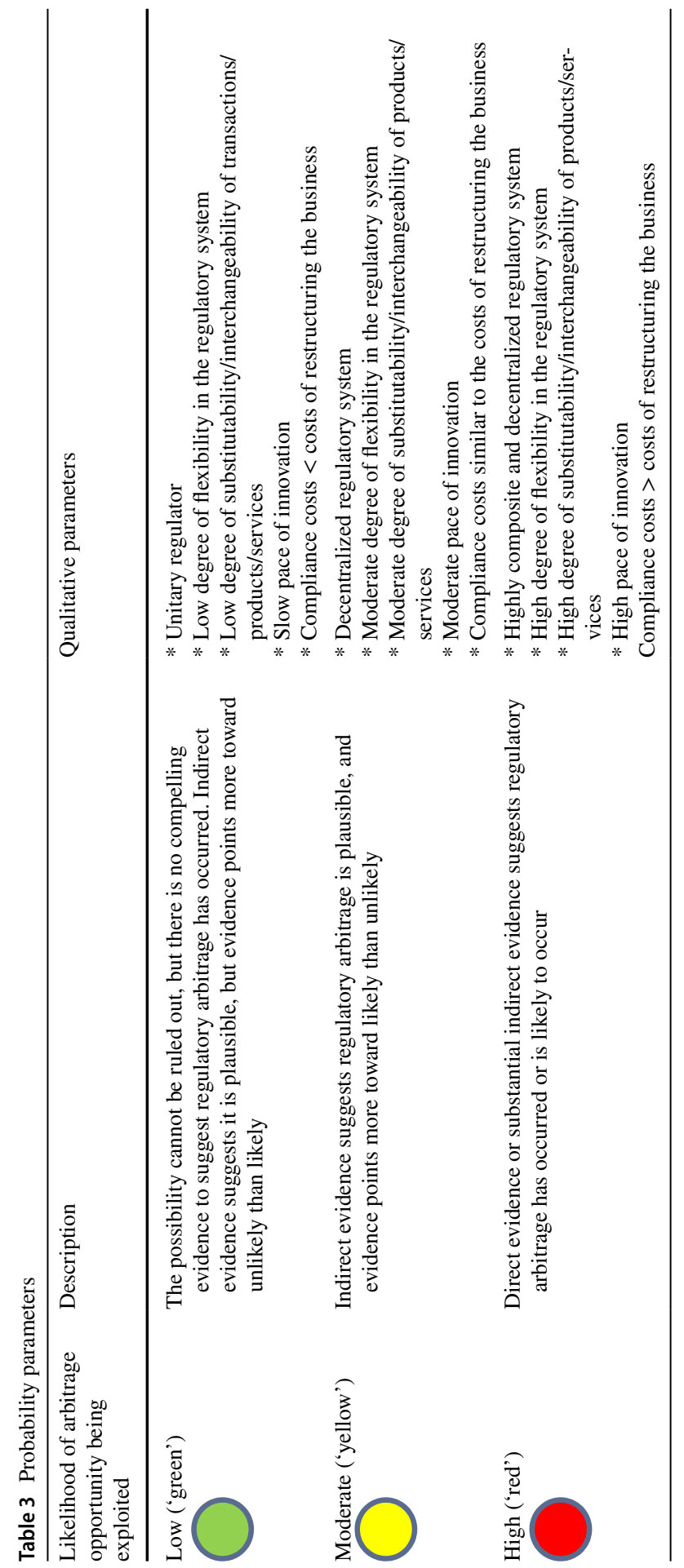


respond when faced with regulatory competition. ${ }^{61}$ The analysis shows that the degree of flexibility in the regulatory design does influence the odds of an arbitrage opportunity emerging. In that respect, the existence of soft law and regulatory standards developed by regulatory agencies (e.g. guidelines) can be regarded as an indicator of higher chances of regulatory arbitrage opportunities unfolding.

\subsection{Degree of Substitutability and Interchangeability of Transactions, Products and Services}

Another indicator for the possibility of regulatory arbitrage practices is the degree of substitutability and interchangeability of transactions, products and services. This is linked to the idea of arbitrage as the exploitation of the discrepancies between the economic substance of a transaction and its legal treatment. The degree to which two transactions are close economic and strategic substitutes but are subject to different regulatory regimes influences the likelihood of arbitrage taking place. ${ }^{62}$ The existence of a high degree of substitutability between services, transactions and products points to a high likelihood of arbitrage occurring.

\subsection{Financial Innovation}

The new opportunities offered by technological innovation can enable market participants to engage in activities and do things that they were not able to do before, or to do things better (or faster) than before, and in the process, to challenge or arbitrage established regulatory architectures. ${ }^{63}$ The wider the innovative solutions and techno-applications, the higher the chance of a regulatory arbitrage opportunity opening up. ${ }^{64}$

\subsection{Compliance Costs vs. Restructuring Costs}

High compliance costs often reflect a 'complex regulatory framework [that] may feature hidden non-linearities and give rise to hard-to-anticipate arbitrage opportunities'. ${ }^{65}$ On the other hand, restructuring a transaction so that it fits under a lighter regulatory regime is not free. Transaction costs associated with setting up the regulatory arbitrage structure most certainly influence the odds of the regulatory arbitrage engagement. ${ }^{66}$ Search costs, bargaining costs, fees for lawyers or investment bankers and other instances of strategic behaviour, and in general, all the costs related to the avoidance strategy have to be carefully examined. Arbitrageurs will conduct a

\footnotetext{
61 Frantz and Instefjord (2014).

62 Fleischer (2010); Partnoy (1997); Turk (2015); Barry (2011).

63 Brummer (2015), pp 977-980; Ford (2017).

64 Lobel (2016); Pollman and Barry (2017), p 383.

65 Gai et al. (2019).

66 Marjosola (2019).
} 
cost-benefit analysis to evaluate whether restructuring costs will exceed compliance costs. If this is not the case, there is a higher likelihood of arbitrage occurring.

\section{Estimating Impact}

Once policy makers have an idea of the probability that a regulatory arbitrage opportunity will be exploited, they have to estimate the potential impact if a risk that could arise as a result of the arbitrage does materialize (see Table 4 below).

A first step involves a comparative assessment of the two sets of regulations, i.e. i) the set of regulations that would be applicable without the regulatory arbitrage scheme and ii) the set of regulations applicable after the arbitrage scheme is in place. To what degree do both achieve the regulatory objective? State of the art comparative law approaches should be applied in this endeavour.

In cases of cross-jurisdictional arbitrage, as a second step policy makers also need to assess whether and to what degree risk is transferred to the other jurisdiction and how it might flow back. There could be situations when moving the business away from one jurisdiction could reduce the risks for that jurisdiction-for instance, the costs of rescuing a financial entity could be (partially) borne by the new home jurisdiction. Conversely, there can be situations where the risk stays in or flows back to the original jurisdiction. For instance, in the case study on Libra presented in Sect. 9 below, it is argued that the risk for the home jurisdiction is not fundamentally reduced because of the dependence of institutions in the system's periphery on the system's core (i.e. the Reserve) that is located in a different jurisdiction.

The next step is to estimate the severity of the increased risk due to the regulatory arbitrage scheme. To this end, we use a two-dimensional framework based on Claudio Borio's 'macroprudential framework for financial supervision and regulation'. ${ }^{67}$

\subsection{Cross-Sectional Dimension}

The first dimension is the cross-sectional dimension (see Table 5). It refers to the marginal contribution that an institution or activity has on system-wide macro risk. In order to determine the cross-sectional impact, several indicators can be used. The most straightforward is using the size of an institution or activity. The idea behind this indicator is that larger institutions or activities are expected to have a greater system-wide significance (all other things being equal).

Another indicator for the cross-sectional dimension is interconnectedness. The greater the interconnectedness of an institution or activity, the larger is the potential risk of contagion and thus the potential impact on the system as a whole if the institution or activity is exposed to a shock.

A third indicator relates to the substitutability or interchangeability of an institution or activity. If an institution or activity is rather unique, and its substitutability is thus

67 Borio (2003). 
Table 4 Potential impact

Is the regulatory objective achieved?

Yes ('green')

No ('red')
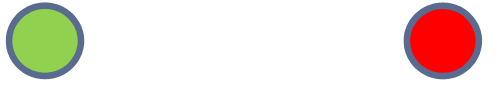

Can risks flow back?

Yes ('red')

No ('green')
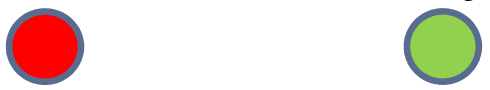

low, its failure can be expected to have a larger impact on the system, ceteris paribus. Risks arising from regulatory arbitrage are thus more likely to be of a systemic nature.

In order to gauge the significance of the cross-sectional dimension-and thus its potential impact-policy makers should assess each indicator's relevance. To this end, it is useful to differentiate between the activity that results from the arbitrage and the institution(s) conducting it. The policy maker should then determine, on a best effort basis, the relative relevance of each indicator for the activity as well as the institution.

Again, each indicator corresponds to a traffic light colour. Filling in the table will yield six traffic lights. It is then up to the policy maker to weigh their relative importance and come to a conclusion on the possible overall impact. For instance, if the indicators show 'medium' for size, and 'none/low' for interconnectedness and substitutability for a given institution, the policy maker can probably assign the indicator for the cross-sectional dimension overall a 'green' light. On the other hand, if a given institution displays 'medium' size, but 'high' interconnectedness and 'medium' substitutability, a policy maker may judge that this combination even warrants a 'red' light overall for this indicator.

\subsection{Time/Cyclical Dimension}

The second dimension is the time (or cyclical) dimension which refers to a variable or type of behaviour that amplifies financial and business cycles (Table 6 below). Determining relevant indicators for this dimension proves more challenging than for the cross-sectional dimension, since cyclical risks mostly also have a structural dimension. For our purpose, we focus on incidences that are deemed to contribute to the build-up of systemic risk, namely the build-up of procyclicality. Procyclicality can occur when the build-up of risks is encouraged during the expansionary phase of the cycle. When market conditions change and the cycle turns, risks materialize, possibly leading to fire-sales and illiquidity spirals and thereby worsening market conditions, which can exacerbate the downturn even further.

The possibility of these risks building up over time can be evaluated using a set of indicators. The first indicator is credit growth and leverage, which are recognized as most prominent. Additionally, asset price growth can give an indication of excessive and unsustainable growth and the build-up of potential vulnerabilities. Another relevant yet hardly measurable phenomenon is the build-up of supposedly liquid 


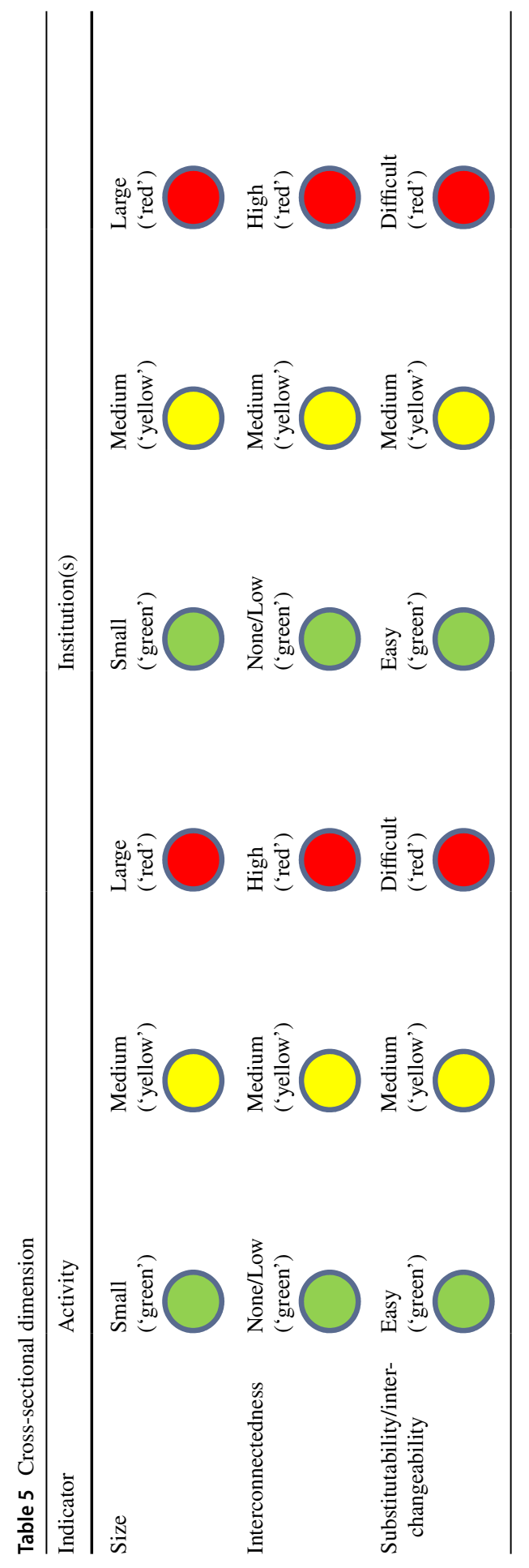


Table 6 Time/cyclical dimension

\begin{tabular}{|c|c|c|c|c|c|c|}
\hline Indicator & Activity & & & Institution( & & \\
\hline Credit growth/leverage & $\begin{array}{l}\text { Small } \\
\text { ('green') }\end{array}$ & $\begin{array}{l}\text { Medium } \\
\text { ('yellow') }\end{array}$ & $\begin{array}{l}\text { Large } \\
\text { ('red') }\end{array}$ & $\begin{array}{l}\text { Small } \\
\text { ('green') }\end{array}$ & $\begin{array}{l}\text { Medium } \\
\text { ('yellow') }\end{array}$ & $\begin{array}{l}\text { Large } \\
\text { ('red') }\end{array}$ \\
\hline Asset price growth & $\begin{array}{l}\text { None/Low } \\
\text { ('green') }\end{array}$ & $\begin{array}{l}\text { Medium } \\
\text { ('yellow') }\end{array}$ & $\begin{array}{l}\text { High } \\
\text { ('red') }\end{array}$ & $\begin{array}{l}\text { None/Low } \\
\text { ('green') }\end{array}$ & $\begin{array}{l}\text { Medium } \\
\text { ('yellow') }\end{array}$ & $\begin{array}{l}\text { High } \\
\text { ('red') }\end{array}$ \\
\hline Liquidity illusion & $\begin{array}{l}\text { Easy } \\
\text { ('green') }\end{array}$ & $\begin{array}{l}\text { Medium } \\
\text { ('yellow') }\end{array}$ & $\begin{array}{l}\text { Difficult } \\
\text { ('red') }\end{array}$ & $\begin{array}{l}\text { Easy } \\
\text { ('green') }\end{array}$ & $\begin{array}{l}\text { Medium } \\
\text { ('yellow') }\end{array}$ & $\begin{array}{l}\text { Difficult } \\
\text { ('red') }\end{array}$ \\
\hline
\end{tabular}

Table 7 Overall assessment

\begin{tabular}{ll}
\hline Factor & Overall \\
& assess- \\
& ment \\
\hline
\end{tabular}

Probability of regulatory arbitrage

Achievement of regulatory objective

Possibility of risks flowing back

Cross-sectional risk

Cyclical risk

assets, i.e. an illusion of liquidity. Favourable market conditions might lead to a misperception of risks, which leads to the build-up of vulnerabilities that can contribute to liquidity spirals in the event of a change in market conditions.

Here, too, the policy maker should come to a judgement on whether this indicator warrants a 'red', 'yellow' or 'green' light overall.

\section{Incorporating the NOAEL Approach and Setting Acceptability Thresholds}

The policy maker should now have a table with five traffic lights reflecting five individual factors. Combining the individual assessments results in an overall assessment of the level of likely adverse effects (Table 7).

Policy makers then need to decide whether the level of risk is acceptable. They can either consider each factor individually or the combined overall level of risk. This can be done by using the NOAEL approach, as explained in Sect. 2; i.e. they can use the indicators to determine whether the overall risk to the financial system exceeds what they consider acceptable. In the absence of direct measurements of 
negative effects, this procedure strives to provide qualitative factors to set a threshold of acceptability for adverse effects.

This idea of 'acceptability' in situations of cause-effect uncertainty underpins our study. The identification of indices for the probability and the impact of regulatory arbitrage - and, hence, the resulting 'traffic-light' approach-is designed to help regulators draw a line between what can be expected to be harmful for financial stability (red light), and what can be considered to have an insignificant impact or no impact at all (green light). The NOAEL method does not eliminate the possibility of harm stemming from a regulatory policy, but it does provide a reasonable degree of assurance - a 'reasonable certainty' - that there will be no harm. From this perspective, the fundamental objective is to determine a safe level of exposure to regulatory arbitrage risk present in the 'regulatory environment' of financial markets, much like the fundamental objective of toxicology is to determine safe levels of exposure to toxicants present in the environment.

Indeed, regulatory toxicology strives to set acceptability thresholds that-with the incorporation of uncertainty factors-define doses that are extremely unlikely to have negative effects on human health. These thresholds-which are also referred to as thresholds of toxicological concern (TTC) ${ }^{68}$ - aim to formalize a system of threshold values below which a very low probability of an appreciable risk to human health (or the ecosystem) exists. This turns out to be an effective way to calculate limits of exposure pragmatically. In keeping with this method, we established a set of threshold values for a group of regulatory arbitrage indicators below which(i.e. in case of a green light) — there should be no appreciable risk to, nor a material impact on, financial stability. On the other hand, yellow and red lights can be assumed to be above the acceptability threshold.

Toxicological approaches to risk assessment expose and characterize causal relations between risks and consequences. Thus, they serve as evaluative aids for the design of policy and regulation by way of setting standards for acceptable risks: all 'green' risks are acceptable, all 'red' risks need to be reduced. The 'yellow' risks require the most political judgement. If they can be reduced without adding too much complexity to regulation, this should be done. But if reducing these risks causes regulation to become needlessly complex, the policy maker needs to carefully weigh the benefits and the costs and may come to the conclusion that the 'yellow' risk is acceptable.

\section{Implications for Regulatory Policy}

This contribution brings a new angle into the debate on harmonization versus arbitrage. It emphasizes risk as a dimension of the analysis, and it identifies a set of parameters that are likely to affect the potential consequences of regulatory arbitrage, which-we believe-decision-making processes should account for. In

${ }^{68}$ Hennes (2012). 
our analysis, we replaced the concept of regulatory arbitrage with the concept of risk resulting from regulatory arbitrage if it takes place. Regulatory arbitrage, as noted many times throughout this essay, means that economically equivalent financial transactions may be subject to different regulatory treatment. In contrast, risk resulting from regulatory arbitrage means the risk that the attainment of a regulatory objective (e.g. financial stability) could be negatively affected as a result of the operation of law and the many other factors which may make the law reach beyond its pure rationalistic content. ${ }^{69}$ This risk characterization of regulatory arbitrage hence illustrates whether - and if so, how - the different regulatory treatment of economically equivalent financial transactions may impinge on the attainment of the regulatory objective in a meaningful way.

Importing the NOAEL approach and regulatory toxicology insights into the discourse leads to a normative application of probabilistic risk assessment based on the relative likelihood of regulatory arbitrage occurring and the magnitude of the potential consequences. Such risk characterization challenges the unfettered push for regulatory harmonization vis-à-vis regulatory arbitrage and, at the same time, presents a method of gauging and addressing the drawbacks of regulatory arbitrage. It helps policy makers to realize and possibly overcome the legal system's limited ability to design formal labels that track the economics of transactions with sufficient precision. ${ }^{70}$ Risk resulting from regulatory arbitrage is thus identified and analyzed through its root causes, but it is then measured and assessed based on its likely outcome. This results in probability and impact scores that are combined into a rating (e.g. a 'traffic light' system) that is intended to frame the regulatory stance-i.e. the actions the regulators should consider taking with respect to a specific risk, and how 'strict' or 'lenient' they should be in their attitude towards it.

Determining a safe level of exposure to risk resulting from regulatory arbitrage also means moving beyond the idea of regulatory harmonization as a panacea and remedy for cross-jurisdictional arbitrage. Instead, rigorous risk identification, assessment and management should be the basis for decisions on regulatory divergence or convergence. In a policy-making and law-making context, our analysis shifts the focus towards an analysis and prediction of what rule making may bring about. If we create rules allowing more flexibility, then we will see higher odds of regulatory arbitrage emerging. If the degree of substitutability between services, transactions and products increases further, then this will lead to a higher likelihood of arbitrage occurring. If an institution or activity grows big in size or increases its interconnections, then the impact and potential negative effects of regulatory arbitrage for financial stability will be higher.

This perspective considers what is motivating regulatory arbitrage and the circumstances under which various policy initiatives might be open to regulatory arbitrage. This exercise is in line with the principles of 'good legislation' entrenched in

\footnotetext{
${ }^{69}$ For a similar perspective as applied to company law, see e.g. Kurer (2015).

70 Annelise Riles argues against the notion 'that regulatory arbitrage can be counteracted only if the rules across all legal systems are harmonized', in part because regulators are one or more steps behind financial market actors: Riles (2014), p 63; see also Gelpern (2014). For Annelise Riles, increasing the cost of regulatory arbitrage transactions that arise from different regulatory regimes with different rules should be an important part of any solution to the competition between harmonization and arbitrage.
} 
many constitutions ${ }^{71}$ and in some supranational provisions. In European Union law, for instance, Article 296 of the Treaty on the Functioning of the European Union (TFEU) sets out that 'legal acts state the reasons on which they are based and shall refer to any proposals, initiatives, recommendations, requests or opinions required by the Treaties'. In the field of environmental policy, the Treaty explicitly requires European authorities to take account of 'available scientific and technical data' and 'the potential benefits and costs of action or lack of action'. ${ }^{72}$ Furthermore, and more generally, the Court of Justice requires EU institutions to observe the principle of legal certainty and to build their decisions on an informed choice. ${ }^{73}$

This analysis of the probability and impact of regulatory arbitrage, as an exercise of good law making, needs to be integrated into the normative legal framework. When a regulatory objective is set, the legislative action (or inaction), its design and the strategy undertaken to achieve that objective should strive to 'realise a selfadjusting harmony of principles, rules and standards' ${ }^{74}$

\section{Potential Financial Stability Risks Originating from Regulatory Arbitrage in the Libra Network}

In 2019, the Libra Association published its first White Paper outlining its plan to set up a global payments system based on its own crypto-coin, Libra. ${ }^{75}$ The plans caused a number of concerns for regulators, supervisory authorities and central banks worldwide. ${ }^{76}$ As a result, the Libra Association published a new White Paper in April $2020^{77}$ that proposed some modifications to the original design of the payments system, taking some of the authorities' concerns into account.

According to the 2020 White Paper, the payment system will be composed of several single-currency stablecoins (e.g. LibraUSD, LibraEUR, LibraGBR, etc.) and a multi-currency stablecoin (Libra). The White Paper states that each singlecurrency stablecoin will be fully backed by a Reserve, which will consist of cash or cash equivalents and very short-term government securities denominated in that currency. The multi-currency stablecoin, Libra, is supposed to be a digital composite

\footnotetext{
71 The French Conseil Constitutionnel rules on the constitutionality of certain laws before they are passed, requiring legal security, foreseeability and clear and simple rules: see also Circulaire du 7.7.2011 relative à la qualité du droit du Premier Ministre, Journal Officiel de la République Française, 8.7.2011.

72 Art. 191(3) TFEU.

73 C-269/90 Hauptzollamt München-Mitte v. Technische Universität München [1991] ECR I-5495.

74 Ernest (1995), p 12.

75 At the time of submitting the final version of this article for publication, the Facebook-backed cryptocurrency Libra seems to be undergoing a metamorphosis. Besides being renamed 'Diem', other more structural changes in the design and functioning of the stablecoin are currently under consideration. Furthermore, it has recently withdrawn its authorisation application in Switzerland. Since changes to its legal set up and business model seem to be ongoing, we are unable to provide our opinion on how such changes will impact the risk of regulatory arbitrage. Consequently, the analysis and its findings are to be confined to the initial characteristics of the Libra project.

76 See, for instance, BIS (2019); FSB (2020).

77 Libra Association (2020).
} 
of some of the single-currency stablecoins with fixed nominal weights. Users in countries that do not have a single-currency stablecoin on the network can access it through the multi-currency stablecoin. The multi-currency Libra coin also operates as a settlement coin in cross-border transactions between different currencies. All conversions between Libra coins and fiat currency or other digital assets are supposed to be conducted by third-party financial service providers, such as primary dealers and virtual asset service providers (VASPs).

\subsection{The Regulatory Environment}

The Libra network is an entire financial ecosystem, consisting of different parts that will be located in different jurisdictions and may be regulated differently. Some components of the ecosystem - in particular the Reserve and the payment settlement system-will be centralized and thus in a single location. Others, such as primary dealers and virtual asset service providers, will be located in many jurisdictions. A recent survey by the Financial Stability Board (FSB) showed that different components of the ecosystem may be subject to very different regulatory treatment in different jurisdictions, and some may be outside the scope of current regulation in some jurisdictions. ${ }^{78}$

From a financial stability perspective, most potential risks emanate from the Reserve. This is also the most crucial point from the perspective of potential risks resulting from regulatory arbitrage. The Reserve will most likely be located and licenced in a single jurisdiction. This opens up the possibility for international regulatory arbitrage since jurisdictions have very different regulatory approaches to financial technology in general and crypto-assets in particular. According to the Libra Association's White Paper, Libra Networks (which will administer the Reserve) is in the process of filing for a payment system licence with the Swiss Financial Markets Authority (FINMA).

As a result, other jurisdictions where Libra will potentially be available have limited say in the regulation and supervision of the Reserve; however, the Reserve may buy, sell and hold (significant) amounts of their short-term government securities and bank deposits, and the Reserve is the final backer of their users' (and primary dealers') claims against Libra coins.

There are some mitigating factors on this dependence on Swiss national authorities, in particular:

- Some international standards are likely to apply to critical functions of the Reserve. The issuance, creation and destruction of stablecoins, and the management of Reserve assets, for instance, are deemed to be subject to the Financial Action Task Force (FATF) standards and the Principles for Financial Market Infrastructures (PFMI), although some of these may be challenging to observe. For Global Stablecoin (GSC) arrangements involving banks, the prudential risks

78 FSB (2020). 
and operational resilience vulnerabilities would be subject to the Basel Framework and Principles for the sound management of operational risk. Depending on the creation/redemption processes, the International Organization of Securities Commissions (IOSCO) Principles for the Regulation of Exchange Traded Funds (2013) could be relevant. Depending on the Reserve's structure, the reserve may also be subject to IOSCO Recommendations on Liquidity Risk Management (2018) or IOSCO Policy Recommendations for Money Market Funds (MMFs) (2012). ${ }^{79}$

- FINMA is in contact with major central banks and supervisory authorities to discuss some regulatory and supervisory issues related to the Libra project.

However, the ultimate supervisory decisions rest with FINMA and-even more importantly - the regulatory set-up is solely determined by the Swiss legislator.

\subsection{Estimating Probability}

Based on what we currently know, the Reserve will probably be located in Switzerland and fall under Swiss regulation. Since there will be only one centralized Reserve for the entire network, all other jurisdictions have limited say on regulatory and supervisory issues relating to this Reserve. Jurisdictions that are not content with the regulatory and supervisory set-up might of course try to prohibit the purchase, use and sale of Libra stablecoins in their jurisdiction. It is, however, unclear how successful this strategy could be. Since Libra will be bought and sold via the internet, users may find a way around the prohibition if Libra is sufficiently attractive from their point of view. Thus, the probability of regulatory arbitrage occurring is high for the Reserve (see Table 8).

\subsection{Estimating Impact}

In order to estimate the possible impact, i.e. the potential risk to financial stability that may arise due to the arbitrage opportunity being taken advantage of, first we have to think about whether the regulatory objective is achieved. The regulatory objective we are concerned with is financial stability. We will ignore other policy objectives, such as investor/consumer protection, combating money laundering and terrorism financing, etc.

Due to the fact that Libra is still working on obtaining its Swiss payment systems licence, at the current juncture it is difficult to judge whether the regulatory requirements will be sufficient to mitigate all potential financial stability risks that may emanate from the Libra Reserve. The Financial Market Infrastructure Act (FMIA) allows for flexibility in imposing regulatory requirements on payment system providers. According to FINMA, it will impose extra requirements on Libra for additional services that pose increased risks. This applies in particular to bank-like

79 Ibid. 
risks. In addition, FINMA will give special consideration to whether strict national and international standards for payment infrastructures and also for combating money laundering can be upheld. ${ }^{80}$ However, since no decision has yet been made by FINMA as regards the actual regulatory requirements, we cannot yet assess the effectiveness of the regulatory regime. Once FINMA's regulatory requirements have been set out, a re-assessment may be warranted.

Instead, we will simply assess whether the project as proposed by the Libra Association in its White Paper v2.0 is designed in a manner that achieves financial stability. The recent White Paper introduces some measures to mitigate potential financial stability risks, such as building up a capital buffer to protect the Reserve against losses, and introducing redemption stays and early redemption haircuts to slow down a potential run on the Reserve.

However, some important vulnerabilities are not addressed in the White Paper v2.0. A main risk is the potential size of the Reserve. If Libra stablecoins turn out to be popular and widely used, the Reserve will be very large. This can result in several potential vulnerabilities. Large movements, in and out, of Libra stablecoins can result in large sales or purchases of safe, liquid assets and thus move market prices. Since each single-currency stablecoin is backed 1:1 by short-term government securities and cash or cash equivalents denominated in its corresponding currency, the composition of the asset portfolio is determined by the demand for the single-currency stablecoins with no portfolio diversification requirements. This may result in cluster risk for both the Reserve as an investor and for governments as issuers and may lead to higher risks in the financial system if a shortage of short-term, highly liquid and safe assets requires other institutional investors to revert to higher risk assets.

Finally, overnight investments of Libra Reserve funds in money-market funds (MMFs) may exacerbate vulnerabilities in these funds. This could happen in two ways: If a run on the Libra Reserve causes the Reserve to withdraw a significant share of their funds from the MMF market, this reduction in demand for MMF shares could lower their prices, leading other investors to sell their MMF shares, too. As a result, MMFs would have to sell assets, which may negatively affect the prices of these assets. A run on MMFs and asset fire sales could be the result. However, the redemption stays and haircuts proposed by the Libra Association are likely to mitigate this risk. Alternatively, a run on MMFs could prompt the Libra Association to withdraw its funds from the MMF market, thus exacerbating a run (and resulting fire sales) that has already started.

Hence, in its current design, the Libra network does not achieve the objective of financial stability.

${ }^{80}$ FINMA (2020). 
Table 9 Libra-impact

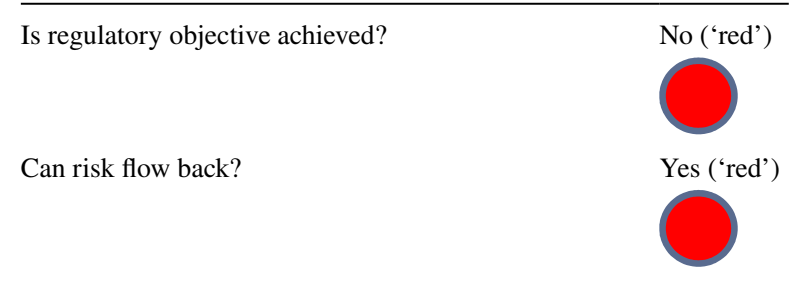

Turning to whether risk can flow back, the answer is yes. The design of the Libra ecosystem with a centralized Reserve in one jurisdiction and designated dealers and VASPs in many jurisdictions allows risk to flow from the Reserve (the system's core) to the jurisdictions that have institutions on the system's periphery (designated dealers and VASPs) (Table 9).

Put another way, risks to financial stability can build up in the Reserve (that is under Swiss regulation and supervision) and then materialize in other jurisdictions (cross-jurisdictional arbitrage).

\subsection{Cross-Sectional Dimension}

\subsubsection{Size}

The size of the Libra Reserve-and the entire ecosystem-will depend on supply and demand for the Libra stablecoins, both the single-currency coins and the multicurrency coin. Demand for Libra coins will depend on a number of factors, such as transaction fees, acceptance by merchants and the ease of access, i.e. the availability of designated dealers and VASPs. The primary target group seems to be consumer payments rather than corporates. But the size of the Libra network also depends on its members. According to the White Paper, membership of the association consists of geographically distributed and diverse businesses and non-profit organizations. ${ }^{81}$ Some of them are large platform providers, such as Lyft and Spotify, which will likely help to create use cases for the stablecoins. The higher the number of platform providers and financial intermediaries, the larger the network effects and thus demand are likely to be. Overall, network effects will probably be decisive in determining the size of the Libra Network and Reserve. If many internet shops and platforms accept Libra stablecoins as a means of payment, it becomes more attractive for payers and payees to use them. Online merchants, in particular those which conduct cross-border business, often face significant costs. If they are able to reduce costs by using the Libra network, they may offer customers discounts in return for payment in Libra stablecoins. Of course, the attractiveness and thus the size of the Libra network will also depend on regulation, but in order to avoid endogeneity, we will disregard this factor in our analysis.

81 Libra Association (2020). 
Remittances already provide a potentially important use case for Libra stablecoins-currently, they tend to be costly and slow. If Libra can offer a cheaper and faster product, there will be a sizeable demand. The World Bank notes that remittances to low and middle-income countries amounted to USD 554 billion in $2019 .{ }^{82}$ In addition, the Libra Association's members will probably develop additional use cases. Consequently, it seems to be safe to assume that Libra will not remain a small niche payment service provider. The ECB undertook size simulations based on three scenarios. In the first scenario, Libra becomes a widespread means of payment; in the second and third scenarios Libra is additionally used as a store of value (the third is an extreme-case scenario). In the first scenario, Libra reaches a global size of EUR 152.7 billion, and in the third (extreme) case a size of EUR 2,928 billion. The ECB estimates that Libra could potentially become one of Europe's largest MMFs. ${ }^{83}$

Thus, while the size of the Libra Reserve depends on how widely it is used for payments, and to what degree users regard it as a store of value and hold it in their wallets rather than converting it back into fiat currency, it seems likely that the Reserve will become large in the medium to long term.

\subsubsection{Interconnectedness}

Due to the design of the Libra ecosystem, its interconnectedness with the traditional financial sector will be high. Libra Networks, which manages the Reserve, will be interconnected with international asset markets-namely those for highly liquid, safe, short-term government securities - and with central securities depositories that provide custody for the Reserve's assets. It will also be interconnected with banksby way of holding deposits - and with MMFs by investing overnight in their shares. Additionally, the White Paper notes that well-capitalized, regulated financial institutions are envisioned to act as designated dealers that make markets, purchase stablecoins from, and sell stablecoins to Libra Networks. Finally, there will also be an interconnection with VASPs, which will provide users with services on the network, such as hosting wallets. Another potential interconnection to the traditional financial system may be by way of financial institutions holding Libra stablecoins. The Libra system will thus be highly interconnected with all parts of the financial system.

\subsubsection{Substitutability}

If Libra becomes a dominant player in the market for payment systems on a global scale, substitutability will be low. It can be assumed that because of network effects there is only room for very few players in the market.

Table 10 summarizes the results of the assessment of the different indicators for the cross-sectional dimension. In sum, from a cross-sectional perspective the impact on financial stability if vulnerabilities of the Libra network materialize can be

\footnotetext{
82 The World Bank (2020).

83 Mitsutoshi et al. (2020).
} 
Table 10 Libra-cross-sectional dimension

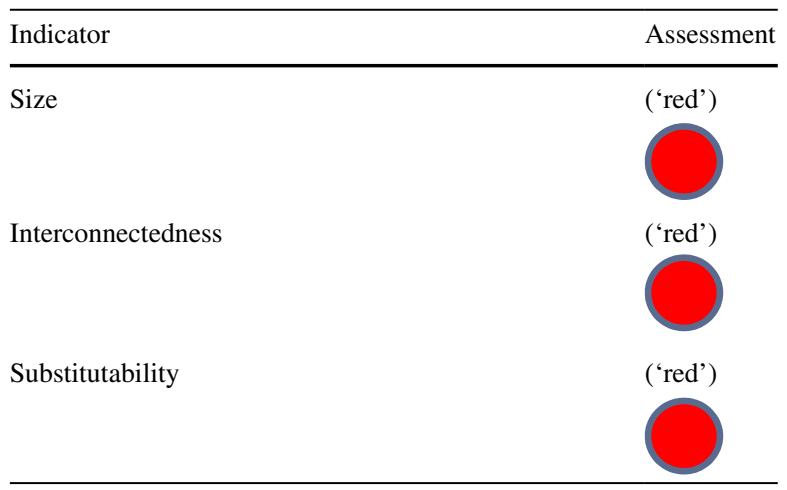

expected to be significant. Therefore, we will assign a red traffic light for the crosssectional dimension overall.

\subsection{Time/Cyclical Dimension}

The first indicator on the time dimension is leverage. It is likely that there will be no leverage in the Libra ecosystem. The White Paper does not foresee the option of providing loans, and the requirement for the stablecoins is to be backed 1:1 by the Reserve. However, in the long term this may change. For the time being, it seems safe to assign this indicator a green traffic light.

The second indicator, asset price growth, is not that clear. In theory, large purchases or sales of assets should not take place if users only use Libra as a payment system. There is a possibility that prices for safe, liquid short-term government securities may increase if the system grows quickly. On the other hand, there should not be much movement from users selling one single-currency stablecoin for another, and there should also not be much portfolio shifting if single-currency stablecoins are backed 1:1 through assets denominated in that currency. The only option for portfolio shifting may be within the Euro area, where a Member State's downgrade could result in the Reserve selling this Member State's bonds and buying those of another, more highly rated Member State instead. Therefore, from a Euro area perspective, we will assign this indicator a yellow traffic light.

In theory, there should be no liquidity illusion. The Reserve will hold only highly liquid, safe assets that it should be able to sell easily and at little loss. Additionally, there will be a capital buffer to prevent losses. The designated dealers are required to make markets in Libra stablecoins. Additionally, the Libra Association wants to develop a mechanism to return funds to end users if designated dealers cease operation for some reason. There is some scope for a liquidity illusion on the part of users, however, in the event of a run. Not all users may be aware that Libra foresees the implementation of redemption stays or haircuts if a run on the stablecoins takes place. However, it seems reasonable to assign this indicator a green light.

With two green lights and a yellow one, we will assign the time dimension a green light overall (Table 11). 
Table 11 Libra-Time/cyclical dimension

Table 12 Libra-overall assessment

\subsection{Overall Assessment}

Combining the assessments for the individual risk (groups) yields Table 12 .

Almost all indicators (except the one for the cyclical risk dimension) yield a red traffic light in our analysis. This means that Libra is a case where regulatory arbitrage could become problematic for the financial system. Regarding the regulation and supervision of the Reserve, national legislators outside Switzerland have limited scope for action. A possible solution would be to agree on international standards for the regulation and supervision of global stablecoin systems, for instance in the FSB.

Such standards could include clearly defined redemption rights for end users as well as the mandatory implementation of liquidity management instruments to slow

\begin{tabular}{l}
\hline Indicator \\
\hline Credit growth/leverage \\
Asset price growth \\
Liquidity illusion
\end{tabular}

Factor

Overall assessment

Probability of regulatory arbitrage

('red')

Achievement of regulatory objective

('red')

Possibility of risks flowing back

('red')

('red')

('green')

Cyclical risk

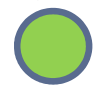


down a possible run on the stablecoin (such instruments are already proposed in the Libra White Paper v2.0). Additionally, there could be international minimum standards for capital buffers in order to mitigate risk from fraud, losses on the asset side, etc.

In addition to such international standards, there are some possibilities for regulators to act on a national level. Designated dealers and VASPs can be regulated nationally. Since these institutions are entry points into the Libra ecosystem for users, they can be regulated on a national level in a manner that aims to protect the domestic financial system as much as possible and that makes entry for domestic users as easy or difficult as desired. Regulated institutions, such as banks, which want to participate in the network have to comply with all banking regulations anyway. Additionally, the holding of coins on the asset side could be regulated in domestic financial regulation in order to limit contagion. Finally, an outright prohibition on buying, holding and selling Libra stablecoins is always an option for national governments. It is not clear, however, how effective such a prohibition will be in practice. Since Libra will be bought and sold via the internet, users may find a way around the prohibition if Libra is sufficiently attractive from their point of view. On the other hand, such passive freedom of services (users in one country use VASPs and designated dealers in a different, less strictly regulated country) is probably limited in practice. Many users will face language barriers, and national authorities can ban any marketing aimed at residents in their jurisdiction.

Of course, not all potential financial stability risks related to Libra result from regulatory arbitrage, but we have disregarded those risks for the purposes of the case study. Moreover, we were unfortunately not able to include any quantitative data in our analysis because Libra is still in the concept stage. It is understood that, ideally, the indicators should be based as much as possible on data and empirical evidence.

\section{Concluding Remarks}

This article advances the scholarship and policy debate surrounding regulatory arbitrage by offering a novel risk assessment. In doing so, it draws upon methodologies from regulatory toxicology due to some common features in risk characterization, namely a wide array of factors such as interconnections and spillover effects that need to be considered, and similar hurdles in collecting and processing relevant scientific information for regulatory risk screening. The literature on regulatory toxicology offers a great deal of experience and solutions in the management of uncertainty relating to data, the adoption and usage of qualitative parameters and the identification of thresholds for policy action and inaction (regulatory triggers) that can aid in developing a framework for managing regulatory arbitrage risk.

This article proposes a framework that helps policy makers assess if a certain instance of regulatory arbitrage is potentially harmful to the attainment of a regulatory objective and needs to be addressed, or if it can safely be ignored.

Framing regulatory arbitrage in terms of risks involves a novel conception and understanding of arbitrage. This risk categorization acknowledges that regulatory arbitrage is a complex phenomenon, and that considerable uncertainty may exist when measuring its contribution to systemic risk. As Roberta Romano points out, 
the uncertainty exacerbates the risk that regulators will get things badly wrong, and with only one regime, regulatory error is much more costly, as it will ripple across the global financial system. With numerous regulatory regimes, there is at least a chance that not all regulators will make the same mistake, and accordingly, thereby not incentivize all financial institutions to follow the same flawed strategy. ${ }^{84}$

The course of action-or reaction - of the regulated entities in response to regulation alters risk in unanticipated ways that evolve non-linearly, 'rendering it extremely difficult to predict the impact of regulation over time'. ${ }^{85}$

Regulations that may be suitable for the pursuit of a certain regulatory objective (financial stability, consumer protection, transparency, etc.) can in fact, when initiated, rapidly become inappropriate or insufficient when a financial system's business, legal and technological conditions change. Besides, regulated entities and individuals adapt their behaviour in response to regulation, and their reactions change over time, interacting with the regulatory environment, in non-linear ways, which greatly complicates an analysis. ${ }^{86}$

Although uncertainty is prevalent due to data gaps and a necessary reliance on models, our analysis proposes qualitative metrics for assessing regulatory arbitrage risks and provides the opportunity to better understand key factors (based on heuristics and literature) that can be used for hazard identification.

Furthermore, focusing on the likelihood of arbitrage actually occurring and the magnitude of the potential risk to financial stability shows that regulatory harmonization may not always be necessary for the problem of regulatory arbitrage. From this point of view, neither regulatory divergence nor regulatory convergence may be desirable. Instead, in situations of contagion risk, regulatory differences might even serve as a 'safety valve' against spreading financial crisis. ${ }^{87}$ From a policy-making perspective, such risk-based analysis enables regulators to focus their attention on those instances of regulatory arbitrage that may indeed be harmful.

Acknowledgements This research has been carried out with the financial support of the Deutsche Bundesbank and under the auspices of the Jean Monnet Chair in Digitalisation in EU Financial Studies (EUDIFIN)-611917-EPP-1-2019-1-IT-EPPJMO-CHAIR. The authors would like to thank the anonymous reviewers for their useful feedback. The authors are also grateful to the Deutsche Bundesbank's staff who contributed to this research and in particular to Thomas Droll for his valuable help and input. In addition, the authors would like to thank Valeria Guidolin and the Silvia Balbo Lab-School of Public Health and Center for Regulatory Toxicology of the University of Minnesota for the insights and feedback given along the way when writing this manuscript.

Funding Open access funding provided by Università Ca' Foscari Venezia within the CRUI-CARE Agreement.

\footnotetext{
84 Romano (2010), p 18.

85 Romano (2014), p 35.

86 Ibid.

87 Romano (2010).
} 
Open Access This article is licensed under a Creative Commons Attribution 4.0 International License, which permits use, sharing, adaptation, distribution and reproduction in any medium or format, as long as you give appropriate credit to the original author(s) and the source, provide a link to the Creative Commons licence, and indicate if changes were made. The images or other third party material in this article are included in the article's Creative Commons licence, unless indicated otherwise in a credit line to the material. If material is not included in the article's Creative Commons licence and your intended use is not permitted by statutory regulation or exceeds the permitted use, you will need to obtain permission directly from the copyright holder. To view a copy of this licence, visit http://creativecommons.org/licen ses/by/4.0/.

\section{References}

Adler M (2005) Against 'individual risk': a sympathetic critique of risk assessment. Univ Pa Law Rev 153:1121-1250

Adler M (2006) Policy analysis for natural hazards: some cautionary lessons from environmental policy analysis. Duke Law J 56:1-50

Adler M (2007) Why de minimis? University of Pennsylvania, Institute for Law \& Economics Research Paper No 07-12; University of Pennsylvania Law School, Public Law Research Paper No 07-26

Amorello L (2018) Macroprudential banking supervision \& monetary policy. Palgrave Macmillan, London

Arcuri A, Dari-Mattiacci G (2010) Centralization versus decentralization as a risk-return trade-off. J Law Econ 53(2):359-378

Arnot JA, Brown TN, Wania F, Breivik K, McLachlan MS (2012) Prioritizing chemicals and data requirements for screening level exposure and risk assessment. Environ Health Perspect 120(11):1565-1570

Awrey D (2011) Regulating financial innovation: a more principles-based alternative? Brooklyn J Corpor Financ Commer Law 5(2):273-315

Barry J (2011) On regulatory arbitrage. Texas Law Rev 89:69-78

Beltratti A, Paladino G (2016) Basel III and regulatory arbitrage. Evidence from financial crisis. J Empir Financ 39:180-196

Benoit S, Colliard JE, Hurlin C, Perignon C (2017) Where the risks lie: a survey on systemic risk. Rev Financ 21(1):109-152

Black J (1997) Rules and regulators. Clarendon Press, Oxford

Black J (2001) Decentring regulation: understanding the role of regulation and self-regulation in a 'post regulatory' world. Curr Leg Probl 54(1):103-146

Borio C (2003) Towards a macroprudential framework for financial supervision and regulation? BIS Working Papers No 128. https://www.bis.org/publ/work128.pdf. Accessed 20 Jun 2021

BIS (2019) G7 Working group on stablecoins_-investigating the impact of global stablecoins. https:// www.bis.org/cpmi/publ/d187.pdf. Accessed 18 Jun 2021

Bowers JW (2002) Incomplete law. Louisiana Law Rev 62(4):1229-1243

Brock W, Rodricks J, Rulis A, Dellarco V, Gray G, Lane R (2003) Food safety: risk assessment methodology and decision-making criteria. Int J Toxicol 22:435-441

Brummer C (2015) Disruptive technology and securities regulation. Fordham Law Rev 84:977-1052

Burk DL (2016) Perverse innovation. Wm Mary Law Rev 58:1-34

Butzbach O (2016) Systemic risk, macro-prudential regulation and organizational diversity in banking. Policy Soc 35(3):239-251

Carpenter R (1995) Limitations in measuring ecological sustainability. In: Trzyna T (ed) A sustainable world: defining and measuring sustainable development. California Institute for Public Affairs, Sacramento, pp 175-197

Carruthers BG, Lamoreaux NR (2016) Regulatory races: the effects of jurisdictional competition on regulatory standards. J Econ Liter 54(1):52-97

Cauble E (2017) Exploiting regulatory inconsistencies. Washington Lee Law Rev 74(4):1895-1952

Cross F, Byrd D, Lave L (1991) Discernible risk-a proposed standard for significant risk in carcinogen regulation. Admin Law Rev 43:61-88

Devins C, Koppl R, Kauffman S, Felin T (2015) Against Design. Arizona State Law J 47:609-681 
Dobris JC (2004) Speculations on the idea of 'speculation' in trust investing: an essay. Real Property Probate Trust J 39:439-447

Douglas M, Wildavsky A (1982) Risk and culture. University of California Press, Berkeley

Dourson ML, Stara JF (1983) Regulatory history and experimental support of uncertainty (safety) factors. Regul Toxicol Pharmacol 3:224-238

EFSA (European Food Safety Authority) (2017) The principles and methods behind EFSA's Guidance on Uncertainty Analysis in Scientific Assessment. https://efsa.onlinelibrary.wiley.com/doi/epdf/10. 2903/j.efsa.2018.5122. Accessed 20 Jun 2021

Ernest J (1995) The idea of private law. Harvard University, Cambridge

Esdaile DJ (1995) Principles, benefits and limitations of the NOEL approach. In: Degen GH, Seiler JP, Bentley P (eds) Toxicology in transition. Archives of Toxicology (Supplement), vol 17. Springer, Cham, pp 37-43

FDA (2007) Toxicological principles for the safety assessment of direct food additives and colour additives used in food. Washington DC. https://www.fda.gov/regulatory-information/search-fda-guida nce-documents/1993-draft-redbook-ii. Accessed 18 Jun 2021

FINMA (2020) Libra Association: FINMA licensing process initiated. https://www.finma.ch/en/news/ 2020/04/20200416-mm-libra/. Accessed 18 Jun 2021

Fisher E (2000) Drowning by numbers: standard setting in risk regulation and the pursuit of accountable public administration. Oxf J Leg Stud 20(1):109-130

Fleischer V (2010) Regulatory arbitrage. Texas Law Rev 89:227-289

Ford C (2017) Innovation and the state: finance, regulation, and justice. Cambridge University Press, Cambridge

Frantz P, Instefjord N (2014) Rules vs principles based financial regulation. https://ssrn.com/abstr act=2561370. Accessed 18 June 2021 or http://dx.doi.org/https://doi.org/10.2139/ssrn.2561370. Accessed 18 Jun 2021

Freixas X, Peydro J-L, Laeven L (2015) Systemic risk, crises, and macroprudential regulation. The MIT Press, Cambridge

FSB (2020) Addressing the regulatory, supervisory and oversight challenges raised by 'global stablecoin' arrangements. Consultative document, April 2020. https://www.fsb.org/wp-content/uploads/P1404 20-1.pdf. Accessed 18 Jun 2021

FSB, IMF, BIS (2011) Macroprudential policy tools and frameworks. Technical Report. https://www.bis. org/publ/othp13.pdf. Accessed 21 Jun 2021

Gai P, Kemp M, Sánchez Serrano A, Schnabel I (2019) Regulatory complexity and the quest for robust regulation. ESRB Reports of the Advisory Scientific Committee, No 8. https://www.esrb.europa. eu/pub/pdf/asc/esrb.asc190604_8_regulatorycomplexityquestrobustregulation e63a7136c7.en.pdf? 9a0883a1438c8d87d55b72b3c583979d. Accessed 20 Jun 2021

Garcia SM, Chen P, Gordon MT (2014) The letter versus the spirit of the law: a lay perspective on culpability. Judgement Decis Making 9(5):479-490

Gelpern A (2014) Exhausting regulatory arbitrage. Jotwell. http://corp.jotwell.com/exhausting-regul atory-arbitrage/. Accessed 18 June 2021 and https://perma.cc/EPS9-V3WG. Accessed 18 Jun 2021

Geradin D, McCahery JA (2005) Regulatory co-opetition: transcending the regulatory competition debate. Amsterdam Center for Law \& Economics Working Paper No 2005-06. https://papers.ssrn. com/sol3/papers.cfm?abstract_id=821087. Accessed 20 Jun 2021

Goodhart CAE, Lastra RM (2010) Border problems. J Int Econ Law 13(3):705-718

Goyal A (2017) Macroeconomics and markets in developing and emerging economies. Routledge, London

Hart HLA (1961) The concept of law. Oxford University Press, Oxford

Hennes EC (2012) An overview of values for the threshold of toxicological concern. Toxicol Lett 211:296-303

Hodgson MJ (2015) Scientists as regulators of default inference: examining the rule-evidence interface in administrative law. J Environ Law 27(2):203-229

International Monetary Fund (2013) Key aspects of macroprudential policy. Technical report. https:// www.imf.org/external/np/pp/eng/2013/061013b.pdf. Accessed 21 Jun 2021

Jokivuolle E (ed) (2018) Shadow banking: financial intermediation beyond banks. SUERF Conference Proceedings, No 2018/1. https://www.suerf.org/docx/s_f5cfbc876972bd0d031c8abc37344c28_ 6951_suerf.pdf. Accessed 20 Jun 2021 
Kalberlah F, Schneider K (1998) Quantification of extrapolation factors: final report of the research project No 11606113 of the Federal Environmental Agency. Schriftenreihe der Bundesanstalt für Arbeitsschutz und Arbeitsmedizin, Fb 797. Dortmund/Berlin

Kavlock R, Chandler K, Houck K, Hunter S, Judson R, Kleinstreuer N, Knudsen T, Martin M, Padilla S, Reif D, Richard A, Rotroff D, Sipes N, Dix D (2012) Update on EPA's ToxCast program: providing high throughput decision support tools for chemical risk management. Chem Res Toxicol 25(7):1287-1302

Krewski D, Brown C, Murdoch D (1984) Determining 'safe' levels of exposure: safety factors or mathematical models? Toxicol Sci 4(3):383-394

Krimsky S, Golding D (1992) Social theories of risk. Praeger, Westport

Kurer P (2015) Legal and compliance risk. A strategic response to a rising threat for global business. Oxford University Press, Oxford

Libra Association (2020) White Paper v2.0. 6 April 2020. https://www.diem.com/en-us/white-paper/. Accessed 21 Jun 2021

Lilienblum W, Dekant W, Foth H, Gebel T, Hengstler JG, Kahl R, Kramer PJ, Schweinfurth H, Wollin KM (2008) Alternative methods to safety studies in experimental animals: role in the risk assessment of chemicals under the new European Chemicals Legislation (REACH). Arch Toxicol 82(4):211-236

Lobel O (2016) The law of the platform. Minnesota Law Rev 101:87-166

Marjosola H (2019) The problem of regulatory arbitrage: a transaction cost economics perspective. Regul Governance 15(2):488-407

Miller CT, Krewskl D, Munro LC (1983) Conventional approaches to safety evaluation. In: Homburger F (ed) Safety evaluation and regulation of chemicals. Karger, Basel, pp 66-76

Mitsutoshi A, Cominetta M, Kaufmann C, van der Kraaij A (2020) A regulatory and financial stability perspective on global stablecoins. ECB Macroprudential Bulletin, 5 May 2020. https://www.ecb. europa.eu/pub/financial-stability/macroprudential-bulletin/html/ecb.mpbu202005_1 3e9ac10eb1. en.html\#toc1. Accessed 18 Jun 2021

Miyazaki H (2013) Arbitraging Japan: dreams of capitalism at the end of finance. University of California Press, Berkeley

McBarnet D, Whelan C (1991) The elusive spirit of the law: formalism and the struggle for legal control. Mod Law Rev 54:848-873

Nabilou H, Pacces AM (2015) The hedge fund regulation dilemma: direct vs. indirect regulation. Wm Mary Bus Law Rev 6:183-236

National Research Council (NRC) (1983) Science and judgment in risk assessment. National Academy Press, Washington

National Research Council (NRC) (2009) Science and decisions: advancing risk assessment. National Academy Press, Washington

Nouy D (2017) Gaming the rules or ruling the game?-How to deal with regulatory arbitrage. Speech at the 33rd SUERF Colloquium Helsinki. https://www.suerf.org/policynotes/1401/gaming-the-rulesor-ruling-the-game-how-to-deal-with-regulatory-arbitrage. Accessed 18 Jun 2021

Oosterloo S, de Haan J (2003) A survey of institutional frameworks for financial stability. DNB Occasional Studies 104, Netherlands Central Bank, Research Department

Partnoy F (1997) Financial derivatives and the costs of regulatory arbitrage. J Corp Law 22:211-227

Partnoy F (2019) The law of two prices: regulatory arbitrage, revisited. Georgetown Law J 107:1017-1043

Pistor K, Xu C (2003) Incomplete law. N Y Univ J Int Law Politics 35(4):931-1014

Pollman E, Barry JM (2017) Regulatory entrepreneurship. Southern California Law Rev 90:383-448

Posner EA, Weyl EG (2012) A proposal for limiting speculation on derivatives: an FDA for financial innovation. Coase-Sandor Institute for Law \& Economics Working Paper No 594

Raz J (1979) The authority of law. Oxford University Press, Oxford

Rezvanfar MA (2014) Benchmark dose. In: Wexler P (ed) Encyclopedia of toxicology, 3rd edn. Elsevier, Oxford, pp 402-406

Riles A (2014) Managing regulatory arbitrage: a conflict of laws approach. Cornell Int Law J 47:63-119

Rodricks J, Starr T, Taylor M (1991) Evaluating the safety of carcinogens in food-current practices and emerging developments. Food Drug Cosmet Law J 46:513-552

Romano R (2010) Against financial regulation harmonization: a comment. Yale Law \& Economics Research Paper No 414. https://ssrn.com/abstract=1697348. Accessed 18 Jun 2021

Romano R (2014) Regulating in the dark and a postscript assessment of the iron law of financial regulation. Hofstra Law Rev 43(1):25-93 
Smaga P (2014) The concept of systemic risk. SRC Special Paper No 5

Smithson M (1993) Ignorance and science. Knowl Creation Diffusion Utilisation 15:133-142

Tarko V, Farrant A (2019) The efficiency of regulatory arbitrage. Public Choice 181(1):141-166

The World Bank (2020) World Bank predicts sharpest decline of remittances in recent history. https:// www.worldbank.org/en/news/press-release/2020/04/22/world-bank-predicts-sharpest-decline-ofremittances-in-recent-history. Accessed 18 Jun 2021

Thiemann M, Tröger TH (2020) The case for a normatively charged approach to regulating shadow banking - multipolar regulatory dialogues as a means to detect tail risks and preclude regulatory arbitrage. SAFE Working Paper No 260; European Banking Institute Working Paper Series No 49

Timur K, Sunstein C (1999) Availability cascades and risk regulation. Stanford Law Rev 51(4):683-768

Turk MC (2015) The convergence of insurance with banking and securities industries, and the limits of regulatory arbitrage in finance. Columbia Business Law Rev 3:967-1061

United States Environmental Protection Agency (2000) Risk characterization handbook. https://www. epa.gov/sites/production/files/2015-10/documents/osp_risk_characterization_handbook_2000.pdf. Accessed 20 Jun 2021

Weiß GN, Bostandzic D, Neumann S (2014) What factors drive systemic risk during international financial crises? J Bank Finance 41:78-96

World Health Organization (WHO) (1994) Environmental health criteria 170: assessing human health risks of chemicals, derivation of guidance values for health-based exposure limits. IPCS, International Programme on Chemical Safety. World Health Organization, Geneva

World Health Organization (WHO) (1999) Environmental health criteria 210: principles for the assessment of risks to human health from exposure to chemicals. IPCS, International Programme on Chemical Safety. World Health Organization, Geneva

World Health Organization (WHO) (2009) Environmental health criteria 239: principles for modelling dose-response for the risk assessment of chemicals. IPCS, International Programme on Chemical Safety. World Health Organization, Geneva

Wynne B (1992) Uncertainty and environmental learning. Glob Environ Chang 2:111-127

Publisher's Note Springer Nature remains neutral with regard to jurisdictional claims in published maps and institutional affiliations.

\section{Authors and Affiliations}

\section{Andrea Minto ${ }^{1,2,3} \cdot$ Stephanie Prinz ${ }^{4}$ Melanie Wulff ${ }^{4}$}

Stephanie Prinz

stephanie.prinz@bundesbank.de

Melanie Wulff

melanie.wulff@bundesbank.de

1 Jean Monnet Professor of Law and Economics, Ca' Foscari University of Venice-EUDIFIN Chair, Venice, Italy

2 Visiting Professor Law, University of Southern Denmark, Odense, Denmark

3 Visiting Professor Law at Cyprus International Institute of Management (CIIM), Nicosia, Cyprus

4 Deutsche Bundesbank, Directorate for General Financial Stability, Makroprudenzielle Überwachung des Nicht-Bankensystems, Frankfurt, Germany 